\title{
When loyalties are divided between teachers and patients
}

\author{
Mark Morris Cassel Hospital, Richmond, Surrey
}

\section{Author's abstract}

Three situations are described where a junior doctor is required by his consultant to do something that he thinks is not in the patient's best interests. The dilemma is explored from the perspective of patients' interests being the doctor's first concerm; of the importance of respect for medical teachers, and of the implications of an apprenticeship model of postgraduate medical training.

In this paper several examples will be used to illustrate an ethical problem which seems to pervade the practice of most doctors in the training grades but which receives little attention. The problem is whether the junior doctor should perform an action that the consultant thinks is appropriate, but which the junior doctor thinks is not in the patient's best interests. By exploring several perspectives on the question, I hope to show that the question is more complex than it appears.

\section{Three vignettes}

An experienced senior registrar in general surgery has a patient in the ward who is suffering from a colonic tumour with evidence of metastatic spread and is all but moribund. The consultant thinks that a laparotomy should be performed urgently in order to assess the degree of local invasion and to effect a palliative procedure. He has to fly off to a conference but has no doubts that his senior registrar is competent to do the job and leaves instructions to this effect. The senior registrar feels differently; the diagnosis is obvious and has been confirmed beyond reasonable doubt; the patient's physical condition is so poor that she might not withstand the anaesthetic and he doubts that available procedures will improve the prognosis. It seems to him that the patient is best left in peace to fade away with some dignity.

A medical junior house officer (JHO) has been caring for an elderly patient being investigated for anaemia. All other investigations point with some certainty to

\section{Key words}

Medical hierarchy; senior and junior doctor professional disagreements; patient interests. one particular diagnosis, with the exception of the sternal marrow, which due to a small sample was inconclusive. Treatment on the basis of the presumptive diagnosis is effective but the consultant thinks the sternal marrow should be repeated for completeness. The patient had a particularly strong reaction to the investigation and is terrified of it being repeated. The JHO thinks that in view of the patient's improvement and the relative certainty of the diagnosis it is not necessary. Privately, the registrar agrees, although he would not take a stand over the issue.

A psychiatric registrar has a chronic schizophrenic patient who leads a chaotic lifestyle and is a considerable burden to his family, always having to be bailed out of financial difficulty and frequently turning up on their doorstep and making a scene. He is also a heavy workload on the psychiatric service, with frequent admissions and self-discharges. He turns up at the hospital one weekend when his responsible medical officer (RMO) is on call. The RMO advises an application for detention under section three of the Mental Health Act (six months). The registrar is sceptical, thinking the benefit would be marginal and that the patient might quickly become institutionalised.

In each of these vignettes the central ethical problem is the same: should the junior practitioner do what he or she thinks is best for the patient, or what the consultant thinks is best?

\section{The interests of the patient are paramount}

The common-sense response to the problem is that any doctor has to do that which is in his or her opinion in the best interests of the patient. This position is supported by the BMA statement on the matter in the Handbook of Medical Ethics. A junior doctor has a 'responsibility' to take account of the advice offered by his senior colleague, but if it is thought to be 'inapplicable' then '... he should seek further specific advice' (1). Presumably in practice, this 'further advice' involves the junior discussing his or her doubts with the senior person, thus enabling the senior to explain the basis of his management plans and for alternatives to be discussed. If the disagreement 
remains unresolved in spite of this procedure, then according to the BMA the required course of action is equally clear. 'The primary responsibility of a junior doctor in a training post is to the patient and he should decline to do anything that is not in the patient's best interests' (2).

In practice, however, things are a little less clear. Any junior doctor asked to do something beyond his or her threshold of what is unethical would refuse but the experience of performing some doubtful investigation or procedure because the senior colleague wishes it must be common. With full wards and stretched staff, decisions have to be made with the minimum of fuss and carried out quickly. There is little time for the junior doctor to formulate objections to a management plan, or to argue the case. When the time comes for consultants to write references for future job applications, those who have persistently voiced their disagreements might be remembered not for their moral integrity, but instead for their 'difficultness'.

\section{Respect for teachers}

The relationship of postgraduate trainee to consultant is that of pupil to teacher. In the Hippocratic Oath, the relationship of students of medicine to their teachers is the first issue addressed. It describes a model of a relationship of strict obedience and respect:

'I will keep this oath and this stipulation - to reckon him who taught me this Art equally dear to me as my parents, to share my substance with him and relieve his necessities if required; to look upon his offspring on the same footing as my own brothers, and to teach them this Art, should they wish to learn it, without fee or stipulation' (3).

In the World Medical Association's Declaration of Geneva, the modern restatement of the Hippocratic Oath, the service required of students to their teachers is to show them the 'respect and gratitude which is their due'. The health of the patient is 'the first concern'. In the event of a disagreement over management, the BMA code of seeking 'further specific advice' directly from the senior colleague demonstrates this respect. Discussion of the difference of opinion obviates the temptation privately to voice doubts and grievances among colleagues and peers.

\section{The superior skill and experience of the teacher}

The relationship of a junior doctor to his consultant has been described as one of 'apprentice' to a tradesman (4). Postgraduate teaching of medicine consists of learning through doing the job. While performing menial tasks to facilitate the practice of his consultant such as re-siting drips, filling in forms and arranging investigations, information, skills and experience are being absorbed. Medical school only teaches a basic science foundation on which the real learning can be built in the role of clinical apprentice. In this model it is not the juniors' place to disagree, as initially at least, they have little or no experience on which to base an opinion, and are likely to be mistaken.

If one bears in mind that the teacher-consultant's judgement, based on superior experience is more likely to be correct than that of his apprentice, the cases described above can be re-appraised. The consultant surgeon may have had in the past a hopeless case of apparently inoperable cancer that turned out to be mimicking a benign pathology, and there are similarities with the present case that it is not possible actually to articulate. The consultant doctor may have a 'hunch' that there is more to the elderly person's anaemia than meets the eye. The case for experience being the most important parameter in making judgements is strongest in psychiatry, where there are fewer objective investigations that determine diagnosis and prognosis.

A second important factor that comes with experience in the practice of medicine is the ability to retain a measure of objectivity. The ability to prescribe a painful investigation which is in the patient's best interests, in the face of his anxiety, distress and physical pain can be very difficult. Only with experience of the escalating problems that can result from inadequate investigation can this be achieved. This aspect might be particularly important in the cas of the sternal-marrow investigation described above where the JHO is especially inexperienced in this regard.

\section{The dilemma}

In spite of the importance of respect for one's teachers and the superior judgement of senior staff, the suggestion that juniors should unthinkingly carry out their consultant's management plans can be objected to on two counts. Firstly, blind acceptance of authority was used as a defence of individuals who had carried out Nazi atrocities; posterity has excluded it as a reasonable defence. Secondly, the accountability of junior doctors is illustrated by the sliding-scale of medical indemnity cover-charges as one climbs the medical ladder. If junior doctors were merely expected to be functionaries, they would pay a nominal sum until reaching consultant status. Thus, as a junior doctor's experience increases, so does his legal and moral accountability. A junior doctor who carries out a procedure which is not in the best interests of the patient cannot shelter behind the fact that his consultant requested it. The junior doctor is a registered medical practitioner in his or her own right, and so is accountable for his or her actions.

We are left, then, with an ethical dilemma. When a junior doctor is instructed to perform an act that he believes not to be in the best interests of the patient, it is not sufficient to stifle protest with the assumption that the 'teacher knows best'. Neither is it satisfactory for a junior doctor to negate the experience and intuitive skill of a senior colleague by refusing to carry out the management he prescribes. 
Mark Morris, $B A, M B, C h B, M R C P s y c h$, is Senior Registrar in Psychotherapy at the Cassel Hospital, Richmond, Surrey.

\section{References and notes}

(1) The handbook of medical ethics. London: British Medical
Association: $35-57$.

(2) See reference (1): 68-80.

(3) See reference (1)

(4) Maguire G P. The psychiatric interview. In: Kendel R E, Zealley A K, eds. Companion to psychiatric studies. Edinburgh: Churchill Livingstone, 1988: 191-206.

\section{News and notes}

\section{Thirty years of bioethics}

The Birth of Bioethics, a conference to celebrate the past 30 years - and the next 30 years - of bioethics in the United States will be held on September 23-24 1992 at the University of Washington, Seattle, Washington, USA.

Thirty years ago, an event in Seattle, Washington, gave birth to a new discipline, bioethics - the study of the ethical implications of medical technology. A committee of laypersons was formed to choose between life and death for persons in desperate need of 'the artificial kidney'.

In the thirty years since that widely publicised and debated event, the ethical study of life-and-death decisions, new forms of reproduction, genetic technologies, research with human subjects and access to health care created a new kind of scholar, the bioethicist, and a new field of study, bioethics.

The discipline of bioethics has, according to historian David Rothman, brought 'a fundamental transformation in the substance and the style of medical decisionmaking'. Bioethics has also affected law and public policy.

The Birth of Bioethics will gather over forty 'pioneers' of bioethics, those who published articles before 1976, to review its past and to preview its future. During the coming thirty years, scientific progress in health care will pose unprecedented ethical challenges. The goal of the conference is to draw together the experience of the discipline's past in order to energise its future.

The Birth of Bioethics is an open conference. All who work in the field of bioethics are invited, as well as health professionals whose daily decisions are touched by ethical questions.

For further information please contact: The Birth of Bioethics organisers, University of Washington, Office of Continuing Medical Education, XF-01 Seattle, Washington 98195, USA.

\section{Apology}

Due to an error in production the colour of the June issue front cover was mistakenly printed in a lighter shade than previous years' June editions. We regret any confusion that this error may have caused to readers. 